\title{
Nanopatterning surfaces by grazing incidence swift heavy ion irradiation
}

\author{
M. Karlušić1 ${ }^{*}$, M. Mičetić ${ }^{1}$, M. Kresić ${ }^{1}$, M. Jakšić ${ }^{1}$, B. Šantić ${ }^{1}$, I. Bogdanović-Radović ${ }^{1}$, S.
} Bernstorff ${ }^{2}$, H. Lebius ${ }^{3}$, B. Ban-d'Etat ${ }^{3}$, K. Žužek Rožman ${ }^{4}$, J. H. O’Connell ${ }^{5}$, U. Hagemann ${ }^{6}$, M. Schleberger ${ }^{6}$

1 Ruđer Bošković Institute, Bijenička cesta 54, 10000 Zagreb, Croatia

2 Elettra-Sincrotrone Trieste, 34149 Basovizza, Italy

3 CIMAP, CEA-CNRS-ENSICAEN-UCN, BP 5133, 14070 Caen Cedex 5, France

4 Jožef Stefan Institute, Jamova cesta 39, 1000 Ljubljana, Slovenia

5 Nelson Mandela University, University way, Summerstrand, 6001, Port Elizabeth, South Africa

6 Fakultät für Physik and CENIDE, Universität Duisburg-Essen, D-47048 Duisburg, Germany

*Corresponding author: marko.karlusic@irb.hr

\begin{abstract}
Nanopatterned surfaces play a key role for many applications exploiting unique features such as an enhanced surface area, long- and short-ranged morphology modulations or a spatial variation of electronic and chemical properties. Ion beam irradiation has been frequently used for nanostructuring bulk materials because it is efficient, fast, and cost-effective. In this paper we show that ion irradiation under extremely grazing incidence in conjunction with other scalable processing methods such as wet etching and thermal annealing, is a perfect tool for nanopatterning of dielectric surfaces. We demonstrate that by tuning ion energy and fluence, one can select different surface nanopattern morphologies like individual chains of nanohillocks, nanostripes, or nanoscaled ripples. Furthermore, chemical etching of the irradiated surface can be used to create a negative replica of the nanopattern as only the material making up the surface track is susceptible to the etching process and is thus removed. Also, a removal of the surface track can be achieved by thermal annealing in vacuum. All these presented strategies open up new ways for achieving control over nanoscale surface modifications using swift heavy ion beams.
\end{abstract}

Keywords: swift heavy ion, ion track, surface engineering, nanopatterning 


\section{INTRODUCTION}

Nanoscale patterning of surfaces using ion-beam sputtering has attracted a lot of interest over the last two decades [1-4]. Typically, high fluences of heavy ions like argon, having a kinetic energy of a few $\mathrm{keV}$, are applied to an initially flat surface. This bottom-up approach enables cost-effective, large area nano-patterning of the surfaces, thus being of interest for various applications [5]. Nanoscale ripples as a special class of nanostructures produced by ion-beam sputtering [6-8], have come into the focus due to the fact that recently highly ordered, defectfree ripples were successfully fabricated $[9,10]$. Other recent findings include the observation of chains of nanodots [11,12], single ion effects on Pt surfaces and in graphene [13-15], the use of $\mathrm{keV}$ cluster ions for surface patterning [16,17], and the use of advanced characterization techniques like grazing incidence small angle x-ray scattering - GISAXS for nanoscale ripple analysis [18-20].

Upon the discovery of the unique features of surface nanostructures (i.e. ion tracks) produced by grazing incidence irradiations with heavy ions at high $\mathrm{MeV}$ energies [21], possible applications have been suggested based on the high degree of periodicity observed in the morphology of each ion track, however hardly any work has been done compared to the low energy ion-beam sputtering. The production of these unique nanostructures formed at the impact sites of the swift heavy ions (SHI) can be controlled to a great degree. A well collimated beam of SHI goes through the material without much deflection, and results in very straight ion tracks all aligned along the same incidence direction. The density of the ion tracks produced at the surface can easily be adjusted by the applied ion fluence, i.e. selected by the irradiation exposure time for the given ion flux. For certain ion type used in irradiation, the length of the ion tracks can be controlled either by the angle of incidence [22] or by tuning the SHI energy [23]. The finer details within the ion track like the size of the individual nanohillocks, and their respective distances, can also be controlled to some degree by choosing a suitable ion energy, incidence angle and type of the material [24]. Up to now, after grazing incidence irradiation, prolonged single ion tracks were observed on surfaces of many materials, with distinct features like chains of nanohillocks [21-27] craters [28,29], nanostripes [30] or a number of aligned nanoholes [31]. Recently, also grove-like track morphologies have been discovered, where material within the ion track was found to be missing [32-34].

Finally, grazing incidence SHI irradiation has also been identified as a powerful tool for nanostructuring 2D materials like graphene and $\mathrm{MoS}_{2}$, when it was demonstrated that rupturing and so-called foldings could be produced in the controlled manner [34-38]. 
Formation of these foldings in 2D materials is less well understood, but apparently the thin interfacial water layer plays a role along with a weakening of interatomic bonds along the ion trajectory [35]. Examples of these different ion tracks on surfaces and 2D materials can be seen in Figure 1.
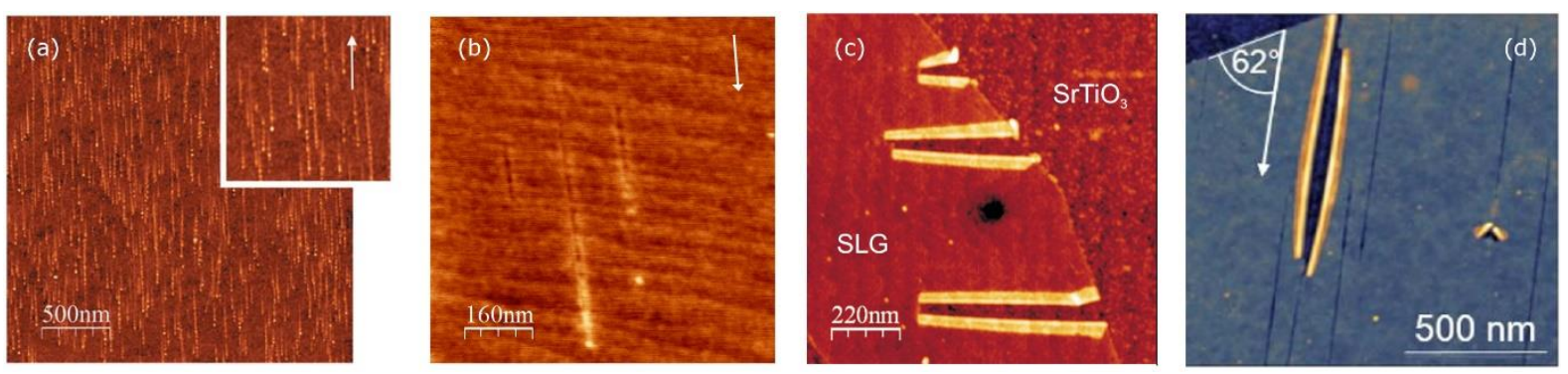

Figure 1. Atomic force microscopy images obtained from various surfaces after grazing incidence irradiation with swift heavy ions. The compilation shows some of the typical patterns: (a) SHI tracks on $\mathrm{TiO}_{2}$ surface [27], (b) groves on $\mathrm{GaN}$ surface [31], (c) foldings in single layer graphene (SLG) supported by $\mathrm{SrTiO}_{3}$ [35], and (d) foldings in $\mathrm{MoS}_{2}$ [37].

The physical processes leading to the observed ion tracks on materials surfaces are reasonably well understood. The passage of the SHI through an insulating material (or wide band gap semiconductors like $\mathrm{GaN}$ [31] or $\mathrm{SiC}$ [30]) generates an intense electronic excitation along its trajectory on the femtosecond time scale. According to the thermal spike models [39], heating of the lattice via electron-phonon coupling occurs on the picosecond time scale. If the density of the energy deposited by the SHI is sufficiently high and well localized, melting of the material can occur along the SHI trajectory. After rapid quenching of the melt on the nanosecond time scale, an ion track as a highly disordered (or even completely amorphous) material will form [39-41], although recrystallization can also play a significant role in this process [42].

Despite all this progress, both on experimental and theoretical grounds, the number of applications which have been realized on the basis of these surface tracks remains limited, probably because the focus so far has been mostly on high energy beams which are not easily available. This is in stark contrast to well established uses of SHI beams, for example in track etched membrane production [43,44] and hadrontherapy [45]. In case of 2D materials, ion tracks observed as foldings having many edge atoms should find applications in filtering, sensing and catalysis [34]. Closed graphene bilayer edges defining the pore in graphene has been suggested as a possible route to improving graphene membrane performance [46]. 
However, possible applications of ion tracks on materials surfaces have not yet been investigated much.

The aim of this work is to pave the way towards possible applications by investigating other modalities of production and manipulation of surface ion tracks. To achieve this, we present our experimental results in two sections. In the first section, we demonstrate how irradiation parameters (SHI type, energy, and fluence) can be fine-tuned to obtain various surface nanostructures like nanostripes and nanoripples. In the second section, we show how post-processing of surface ion tracks like etching and annealing can offer even more possibilities in surface nanopatterning.

Besides outlining strategies for nanopatterning surfaces by SHI, materials used in this work have also possible applications related to the use of SHI beams. Indium tin oxide (ITO) films have been used nowadays as conductive yet transparent material. While not the topic of the present work, introducing line defects like ion tracks could influence its optoelectronic properties by making them anisotropic. Furthermore, ultrathin films and 2D materials can lead to various ion track morphologies due to the confinement of the deposited energy $[29,37,47]$. Other two materials used in the present study, namely $\mathrm{SrTiO}_{3}$ and $\mathrm{SiO}_{2}$, are both of importance in nuclear waste management. Long-term storage of radioactive waste should consider not only radiation damage to material but also changes due to high temperatures and leaching [48-50]. Furthermore, these oxides are important in electronics industry where both etching and annealing are common processing procedures to remove defects and improve the quality of samples [51,52].

From more general point of view, nanoscale surface modifications produced by grazing incidence swift heavy ions should be applicable to many different dielectrics and semiconductor materials. Therefore, these nanoscale modifications of the surfaces could find possible applications when manipulating surface properties like adhesion, wettability and biocompatibility is needed. Also, ordered growth of the nanoparticles or influencing properties of supported 2D materials can be easily envisaged on the nanorippled surfaces. 


\section{MATERIALS AND METHODS}

The first set of samples consists of $5 \mathrm{~nm}$ thin amorphous ITO film deposited at room temperature on a Si substrate by magnetron sputtering deposition at the Ruđer Bošković Institute (RBI). These ITO films have been enriched with germanium, with Ge atomic percentage up to $10 \%$. After deposition, the samples were irradiated by SHI at a grazing incidence angle of $\phi=1^{\circ}$ with respect to the surface, using $92 \mathrm{MeV} \mathrm{Xe}^{23+}$ at GANIL (Caen) and $23 \mathrm{MeV} \mathrm{I}^{6+}, 15 \mathrm{MeV} \mathrm{Si}^{4+}, 6 \mathrm{MeV} \mathrm{Si}^{3+}$ and $3 \mathrm{MeV} \mathrm{O}^{2+}$ at $\mathrm{RBI}$ (Zagreb). The applied fluences ranged from 5 tracks $/ \mu \mathrm{m}^{2}$ up to 350 tracks $/ \mu \mathrm{m}^{2}$ on the surface. To achieve the highest track density, by considering irradiation geometry, the SHI fluence of $2 \times 10^{12}$ ions $/ \mathrm{cm}^{2}$ was needed.

A second set of samples consists of quartz $\mathrm{SiO}_{2}(0001)$ and $\mathrm{SrTiO}_{3}(100)$ single crystals and $300 \mathrm{~nm}$ thermally grown $\mathrm{a}-\mathrm{SiO}_{2}$ on $\mathrm{Si}$ wafer. All these samples have been purchased from Crystec GmbH, Germany. The single crystals had epi-ready surfaces, and the a-SiO 2 surfaces have also been found suitable for AFM imaging. These samples have been irradiated at the RBI (Zagreb) using $23 \mathrm{MeV} \mathrm{I}^{6+}$ at a grazing incidence angle of $\phi=1^{\circ}$ with fluences yielding typically 50 tracks $/ \mu \mathrm{m}^{2}$ up to 500 tracks $/ \mu \mathrm{m}^{2}$ on the surface. To achieve the highest track density, by considering irradiation geometry, the SHI fluence of $2.85 \times 10^{12}$ ions $/ \mathrm{cm}^{2}$ was needed. After irradiation, the $\mathrm{SrTiO}_{3}$ samples have been etched for 20 minutes in $\mathrm{HNO}_{3}$ following the procedure given by [53]. All $\mathrm{SiO}_{2}$ samples, both quartz and amorphous $\mathrm{SiO}_{2}$, have been subjected to annealing in vacuum for one hour at temperatures between $400-950{ }^{\circ} \mathrm{C}$. All irradiation parameters are given in the Table 1.

\begin{tabular}{|c|c|c|c|c|c|}
\hline Material & $\begin{array}{l}\text { Density } \\
{\left[\mathrm{g} / \mathrm{cm}^{3}\right]}\end{array}$ & $\begin{array}{c}\text { Ion type and } \\
\text { energy }\end{array}$ & $\begin{array}{c}\text { Electronic } \\
\text { stopping } \\
\mathrm{dEe} / \mathrm{dx} \\
{[\mathrm{keV} / \mathrm{nm}]}\end{array}$ & $\begin{array}{c}\text { Nuclear } \\
\text { stopping } \\
\mathrm{dEn} / \mathrm{dx} \\
{[\mathrm{keV} / \mathrm{nm}]}\end{array}$ & $\begin{array}{l}\text { Range } \\
{[\mu \mathrm{m}]}\end{array}$ \\
\hline $\begin{array}{c}\mathrm{ITO} \\
\left(\mathrm{In}_{2} \mathrm{O}_{3} / \mathrm{SnO}_{2}\right. \\
90 / 10 \mathrm{wt} \%)\end{array}$ & $6.8^{[55]}$ & $\begin{array}{c}92 \mathrm{MeV} \mathrm{Xe}^{23+} \\
23 \mathrm{MeV} \mathrm{I}^{6+} \\
15 \mathrm{MeV} \mathrm{Si}^{4+} \\
6 \mathrm{MeV} \mathrm{Si}^{3+} \\
3 \mathrm{MeV} \mathrm{O}^{2+}\end{array}$ & $\begin{array}{l}21.03 \\
8.09 \\
6.07 \\
4.54 \\
2.62\end{array}$ & $\begin{array}{l}0.21 \\
0.56 \\
0.02 \\
0.04 \\
0.02\end{array}$ & $\begin{array}{l}8.04 \\
4.27 \\
3.86 \\
2.26 \\
1.92\end{array}$ \\
\hline
\end{tabular}




\begin{tabular}{|c|c|c|c|c|c|}
\hline $\mathrm{SrTiO}_{3}$ & $5.13^{[56]}$ & $23 \mathrm{MeV} \mathrm{I}^{6+}$ & 8.96 & 0.48 & 4.08 \\
\hline Quartz $\mathrm{SiO}_{2}$ & $2.62^{[57]}$ & $23 \mathrm{MeV} \mathrm{I}^{6+}$ & 6.21 & 0.31 & 6.04 \\
\hline $\mathrm{a}^{\left[\mathrm{SiO}_{2}\right.}$ & $2.23^{[58]}$ & $23 \mathrm{MeV} \mathrm{I}^{6+}$ & 5.29 & 0.26 & 7.09 \\
\hline
\end{tabular}

Table 1. Irradiation parameters used in this work, as determined by the SRIM code [54].

The structural properties of irradiated samples were inspected in tapping mode atomic force microscopy using a Dimension 3100 AFM (Veeco Metrology, Santa Barbara, CA, USA) and NCHR cantilevers (Nanosensors, Neuchatel, Switzerland) with cantilever resonance frequencies around $300 \mathrm{kHz}$. Images were analysed using the WSXM code [59]. From the raw data (512x512) only a parabolic background was subtracted.

The analysis of irradiated ITO thin film samples was complemented with a novel approach using the grazing incidence small angle X-ray scattering (GISAXS) technique $[27,31,60]$. Those measurements were done at the Elettra Synchrotron in Trieste (Italy) using $8 \mathrm{keV}$ photons and a 2D Pilatus3 1M detector system (Dectris Ltd., Switzerland).

Additionally, etched $\mathrm{SrTiO}_{3}$ samples have been investigated by high resolution scanning transmission electron microscopy (HRSTEM) using an aberration corrected JEOL ARM200F. TEM lamellae were prepared by the focused ion beam (FIB) liftout technique using an FEI Helios Nanolab 650 dual beam system. Prior to exposing the surface to Ga ions, a 300 $\mathrm{nm}$ thick initial carbon layer was deposited using only the electron beam. The specimen plane was aligned with the surface track direction. 


\section{RESULTS}

\section{Influence of the ion energy and fluence}

After low fluence grazing angle SHI irradiation (typically 10 tracks $/ \mu \mathrm{m}^{2}, \phi=1^{\circ}$ ), single ion tracks as shown in Fig. 2 can be observed on the ITO surface by means of AFM. The typical morphology of ion tracks as chains of nanohillocks is observed for samples irradiated by 23 MeV I, $15 \mathrm{MeV}$ Si and $6 \mathrm{MeV}$ Si (Fig. 2(b-d)). However, no tracks were observed after $3 \mathrm{MeV}$ O irradiation, indicating that a threshold for the surface ion track formation exists, and is found to be between $3 \mathrm{MeV} \mathrm{O}$ and $6 \mathrm{MeV} \mathrm{Si}$. After $92 \mathrm{MeV}$ Xe irradiation, single ion tracks in the form of nanostripes appear as shown in Fig. 2(a). We attribute this striking change in track morphology to the limited thickness of the ITO film and the high value of electronic stopping for the $92 \mathrm{MeV}$ Xe beam. Although the influence of the thickness of the film is one of the contemporary research topics $[29,47]$, the observed nanostripes consisting of two parallel chains of nanohillocks are much more reminiscent of rupturing and folding as observed in $\mathrm{MoS}_{2}$ [37]. Note, that the efficiency for ion track formation (with exception for $3 \mathrm{MeV} \mathrm{O}$ irradiation) is close to 1 .

To further analyze our samples, we took GISAXS maps of the tracks which are shown in Fig. 2(e)-(1). In contrast to AFM images which yield information from a very small surface area, GISAXS provides detailed statistical information from the almost whole sample surface area. All GISAXS maps show a characteristic signal of the track formation [27,31], even for 6 $\mathrm{MeV}$ Si ions where the tracks observed by AFM were already very faint. Two characteristic azimuthal angles were measured for each sample: with the probing X-ray beam parallel to the tracks $\left(\theta=0^{\circ}\right)$ or forming an angle of $5^{\circ}$ with the ion tracks $\left(\theta=5^{\circ}\right)$. Using these angles enables us to study the tracks structural properties [60]. The GISAXS signal contains two main contributions: the shape factor - related to the shape of the formed nano-hillocks, and the structure factor which describes their arrangement in the space. The form factor produces a semi-circular signal arround the origin of the Q space, while the structure factor produces a tail-like intensity peaks for the maps measured at $\theta=5^{\circ}$. In addition to these two main factors, there are other contributions like scattering from the surface rougness in the space between the nanohillocks. However that gives the strongest contribution close to the $\mathrm{Q}_{\mathrm{y}}=0$, and it is not taken into account in the detailed GISAXS analysis. The GISAXS map of the film having double tracks, shown in Fig. 2(e), presents two lateral maxima. They are related to the chains 
in the double-stripes (AFM image in Fig. 2(a)). While the other maps do not show such behavior, a characteristic 'tail' is visible in all GISAXS maps measured with $\theta=5^{\circ}$. The shape of this tail is related to the length of the tracks [60] and to the shape of the nanostructures formed by the ion passage. We have performed a numerical analysis of the ion tracks using the models for the GISAXS description presented in Ref. [60]. Two models have been used for the data evaluation from Fig. 2. All of them assumes formation of nanohillocks within the ion track. The models are illustrated in Fig. 2(m) and (n). The nanohillocks within the track are separated by basis vector $\boldsymbol{a}_{1}$ for both models. Model 1 describes the uncorrelated single ion tracks. As explained in the Ref. [60] this model describes well the single ion tracks formed after low-fluence irradiation, when the ion tracks do not overlap. The position of the $n^{\text {th }}$ nanohillock within the ion track is given by vector $n \boldsymbol{a}_{1}$. Model 2 describes the uncorrelated double tracks formed after single ion passage. Similar to Model 1, these tracks are formed after low-fluence irradiation of the material. The track consists of two parallel rows of nanohillocks separated by basis vector $\boldsymbol{a}_{2}$, that is perpendicular to the basis vector $\boldsymbol{a}_{1}$ describing the positions of the nanohillocks in each row of the double track (in the same way as for the Model 1).

So, for the double tracks we have used the Model 2 (Fig. 2(n)) from Ref. [60], while for all others we used Model 1 (Fig. 2(m)) for uncorrelated ion tracks. The results of the analysis provide us with all main structural parameters of the tracks and are given in Table 2. For the double tracks, shown in Fig 2(a),(e) and (i), the distances between nanohillocks in the direction of the track $\left(a_{1}\right)$, and between the two parallel tracks $\left(a_{2}\right)$ are determined, as well as the number of periods along the track $\left(\mathrm{N}_{1}\right)$, and the corresponding disorder parameters $(\sigma)$. The average track length can be calculated from the number of periods and the distance between the nanohillocks. The properties of the nanohillocks are also determined including their size properties $R_{x}, R_{y}$, and $R_{z}$, i.e. their radii in the directions parallel, perpendicular and vertical to the track direction, respectively. It is interesting to note that the change of the ion type used for the irradiation causes the formation of completely different ion tracks. Thus, for the Xe ions with the highest kinetic energy and electronic stopping, long double tracks are formed $\left(\mathrm{N}_{1}=22\right.$, $\left.a_{1}=26 \mathrm{~nm}\right)$ ), while for the I ions, the tracks are much shorter $\left(N_{1}=11, a_{1}=26 \mathrm{~nm}\right)$. The other two ion beams produce smaller nanohillocks, with the similar total track lengths.

Track formation after grazing incidence irradiation can be used to accomplish an even stronger modification of the ITO surface. By increasing the ion fluence one can leave the regime of isolated tracks and move towards overlapping tracks. As an example see AFM images shown in Fig. 3(a-d), where this regime of ripple formation is reached at typically 350 
tracks $/ \mu \mathrm{m}^{2}$. Obviously the most suitable SHI beams for ripple formation are $15 \mathrm{MeV}$ Si and 6 $\mathrm{MeV} \mathrm{Si}$, as shown on Fig. 3b,c because the more energetic $23 \mathrm{MeV}$ I irradiation produces ripples containing many discontinuities and larger agglomerates (Fig. 3a), while $3 \mathrm{MeV} O$ irradiation is not sufficiently energetic to produce pronounced ripples (Fig. 3d). The corresponding GISAXS maps of the surfaces with nanoscale ripples are shown in Fig. 3(e)-(l), and the results of the GISAXS analysis are given in Table 3. The structural parameters given in Table 3 are obtained by fitting of the GISAXS maps shown in Fig. 3. For the fitting we have used the model for correlated ion tracks (Model 3 shown in Fig. 3(m) from Ref. [60]). Model 3 describes the correlated ion tracks. They form after high-fluence irradiation, i.e. when the same place of the surface is irradiated many times. As visible from the scheme shown in Fig. $3(\mathrm{~m})$, that model assumes that the track separations are correlated, i.e. their values deviate around some specific value $\left(\left|\boldsymbol{a}_{2}\right|\right)$. These tracks are typically formed after irradiation with higher ion fluences leading to strongly overlapping tracks. To describe the correlated ion tracks we assume that the single ion tracks make long chains along the $\mathrm{x}$ direction, consisting of single tracks repeating with the vector $\boldsymbol{a}_{3}=\mathrm{N}_{1} \boldsymbol{a}_{1}$. There are $\mathrm{N}_{3}$ tracks in the x-direction, so the total length of one track chain is $\left|\boldsymbol{a}_{3}\right| \mathrm{N}_{3}$.

The longest tracks and the largest nanohillocks are formed for the $23 \mathrm{MeV}$ I ions. The nanohillocks' sizes decrease with decreasing of the used electronic stopping. The deviation in the direction perpendicular to the ion track $\left(\sigma_{\mathrm{y}}{ }^{2}\right)$ is the largest for the S5 and S8 films, while the deviation of the nanohillock positions in the same direction, but within the ion track $\left(\sigma_{\mathrm{y}}{ }^{1}\right)$ is the largest for the S5 film. This finding is confirmed by the AFM images of these films. 

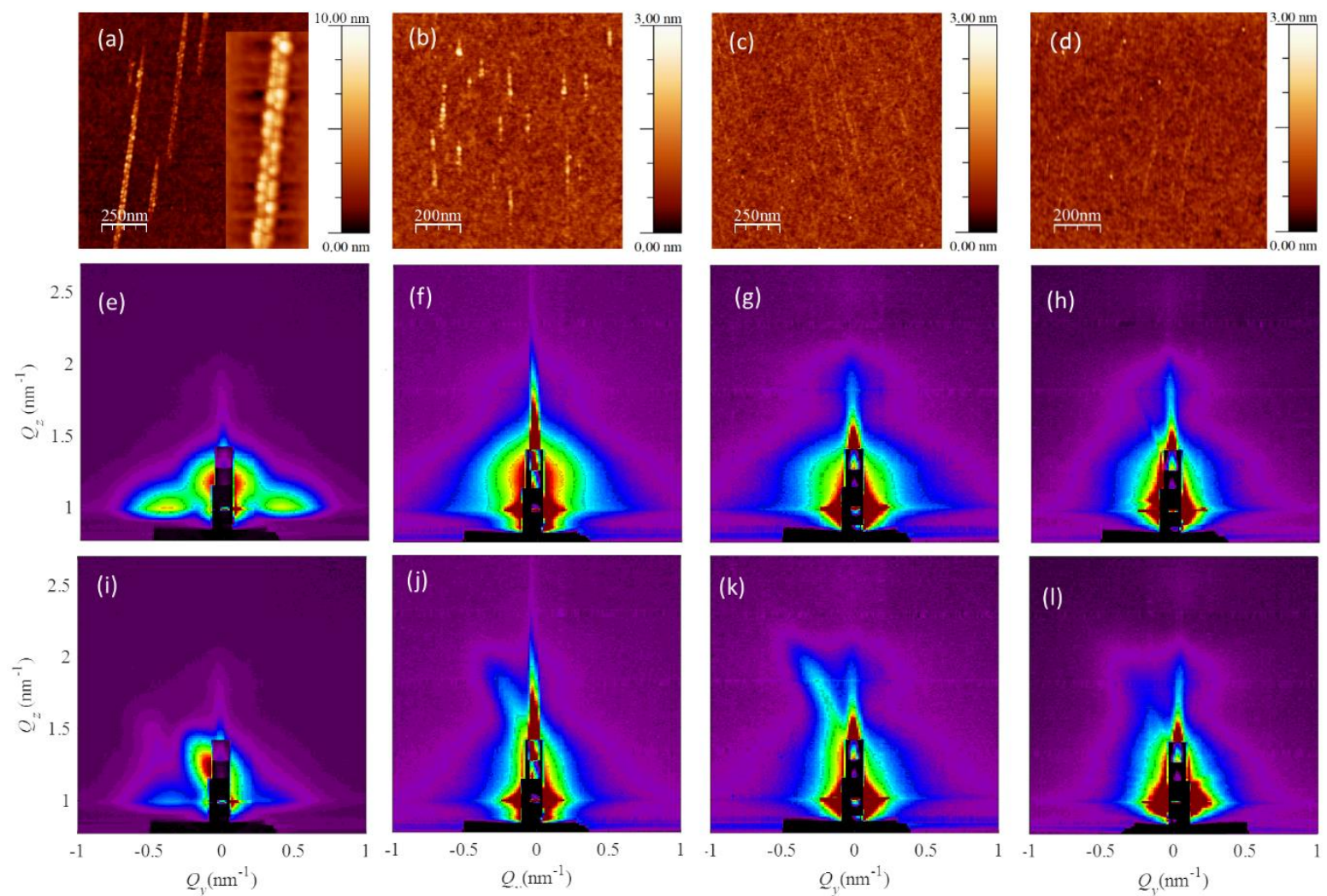

(m) Model 1

(n) Model 2
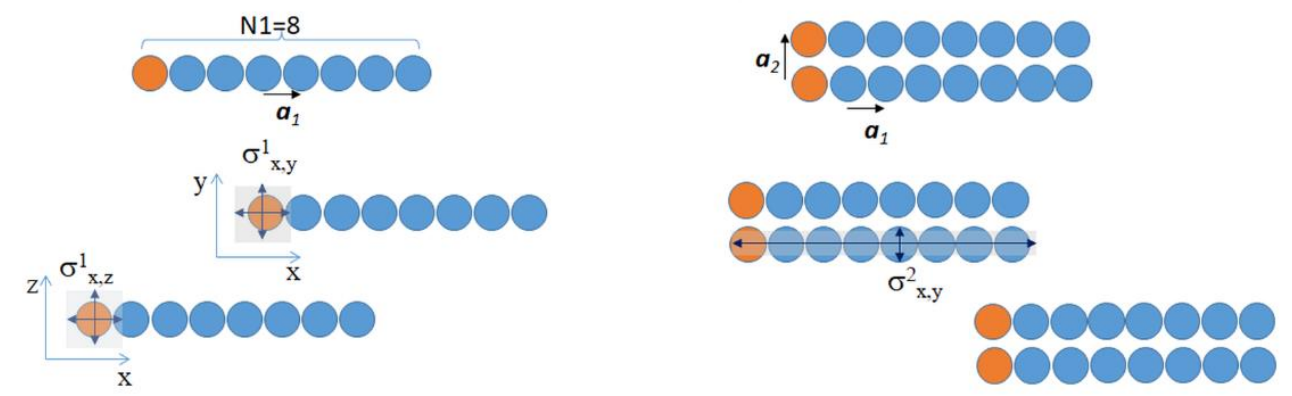

Figure 2. Single ion tracks on the surfaces of thin ITO films (samples S1-S4), observed by AFM after grazing angle SHI irradiation by (a) $92 \mathrm{MeV}$ Xe, fluence 5 tracks $/ \mu \mathrm{m}^{2}$ with inset showing 6x digital zoom (b) $23 \mathrm{MeV}$ I, fluence 20 tracks $/ \mu \mathrm{m}^{2}$ (c) $15 \mathrm{MeV} \mathrm{Si}$, fluence 20 tracks $/ \mu \mathrm{m}^{2}$ (d) $6 \mathrm{MeV} \mathrm{Si}$, fluence 20 tracks $/ \mu \mathrm{m}^{2}$. Corresponding GISAXS maps of the tracks for $\theta=0^{\circ}(\mathrm{e})-(\mathrm{h})$ and $\theta=5^{\circ}(\mathrm{i})-(\mathrm{l})$. The AFM image and the GISAXS maps of the same sample are shown in the same column of the figure. $(\mathrm{m})$ schematics of the Model 1 used in the analysis of single ion tracks. (n) schematics of the Model 2 used in the analysis of double tracks. 


\begin{tabular}{|c|c|c|c|c|c|c|c|c|c|c|c|c|c|c|}
\hline & $\left|a_{1}\right|$ & $\left|a_{2}\right|$ & $\mathrm{N}_{1}$ & $\mathrm{~N}$ & $\sigma_{x}^{1}$ & $\sigma_{\mathrm{y}}{ }^{1}$ & $\sigma_{x}^{2}$ & $\sigma_{\mathrm{y}}^{2}$ & $\sigma_{z}^{1}$ & $\sigma_{z}^{2}$ & $\mathrm{R}_{\mathrm{x}}$ & $\mathrm{R}_{\mathrm{y}}$ & $\mathrm{R}_{\mathrm{z}}$ & $\sigma_{\mathrm{R}}$ \\
\hline$S$ & 26 & $2.6 \pm$ & 22 & 2 & $2.5 \pm$ & $1.8 \pm$ & $2.6 \pm$ & $2.6 \pm$ & $0.10 \pm$ & $2.0 \pm$ & $2.9 \pm$ & $2.5 \pm$ & $2.8 \pm$ & $1.1 \pm$ \\
\hline 1 & \pm 2 & 0.5 & \pm 2 & & 0.7 & 0.3 & 0.5 & 0.5 & 0.05 & 0.1 & 0.1 & 0.1 & 0.3 & 0.3 \\
\hline$S$ & 26 & --- & 11 & - & $17 \pm 1$ & $0.7 \pm$ & --- & --- & $0.21 \pm$ & --- & $3.3 \pm$ & $2.6 \pm$ & $1.9 \pm$ & $0.6 \pm$ \\
\hline 2 & \pm 2 & & \pm 2 & - & & 0.6 & & & 0.05 & & 0.2 & 0.1 & 0.2 & 0.2 \\
\hline$S$ & 33 & --- & 10 & - & 23.5 & $2.4 \pm$ & --- & --- & $0.21 \pm$ & --- & $3.0 \pm$ & $2.0 \pm$ & $1.7 \pm$ & $0.2 \pm$ \\
\hline 3 & \pm 2 & & \pm 3 & - & \pm 0.8 & 0.7 & & & 0.05 & & 0.2 & 0.1 & 0.2 & 0.1 \\
\hline$S$ & 37 & --- & $6 \pm$ & - & 21.4 & $1.9 \pm$ & --- & --- & $0.13 \pm$ & --- & $2.4 \pm$ & $3.2 \pm$ & $1.7 \pm$ & $0.6 \pm$ \\
\hline 4 & \pm 3 & & 3 & - & \pm 0.8 & 0.8 & & & 0.05 & & 0.2 & 0.1 & 0.2 & 0.1 \\
\hline
\end{tabular}

Table 2. Structural properties of the low-fluence induced ion tracks (samples S1-S4). The basis vectors $\boldsymbol{a}_{1}, \boldsymbol{a}_{2}$ define the ideal positions of the nanohillocks in the lattice. $\mathrm{N}_{1}, \mathrm{~N}_{2}$ are the number of periods in $\mathrm{x}$ and $\mathrm{y}$ directions, respectively, and the disorder parameters $\sigma_{\mathrm{x}-\mathrm{z}}{ }^{1}$ and $\sigma_{\mathrm{x}-\mathrm{z}}{ }^{2}$ describe the deviation of the nanohillock positions from the ideal ones. $R_{\mathrm{x}}, R_{\mathrm{y}}$ and $R_{\mathrm{z}}$ are island radii in $x, y$, and $z$ directions respectively, $\sigma_{\mathrm{R}}$ is the standard deviation of the size distribution. All parameters except $\mathrm{N}_{1}$ and $\mathrm{N}_{2}$ (dimensionless) are given in $\mathrm{nm}$. 

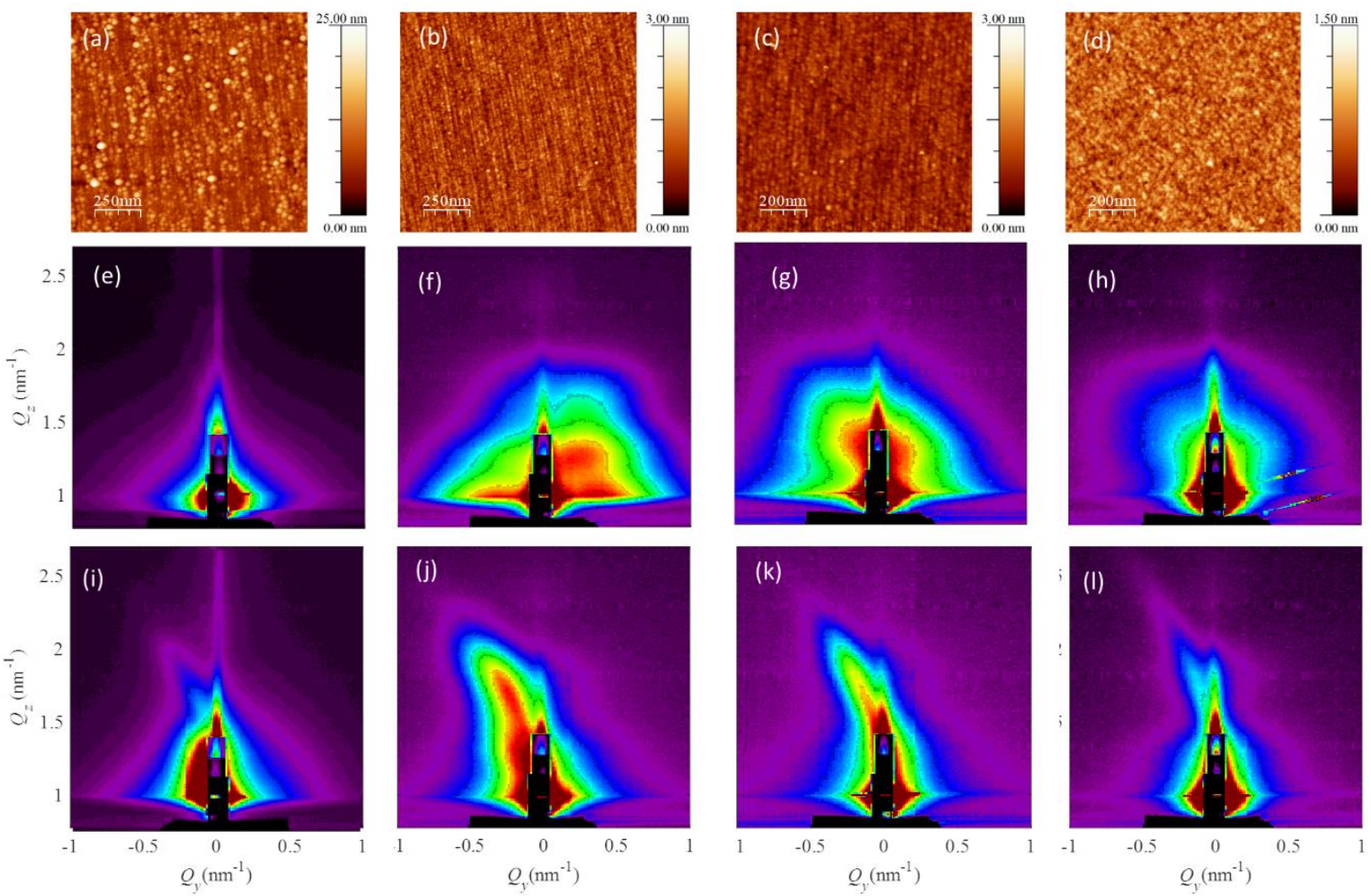

(m) Model 3

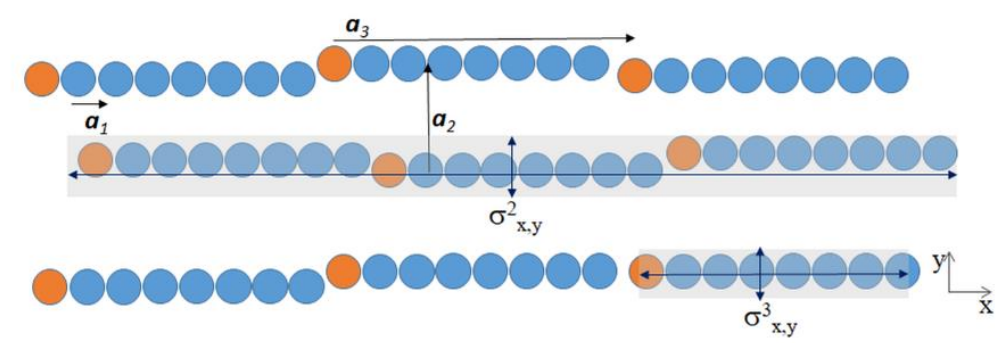

Figure 3. AFM images taken from SHI induced ripples on thin ITO films after grazing angle irradiation (samples S5-S8) by (a) $23 \mathrm{MeV}$ I, fluence 350 tracks $/ \mu \mathrm{m}^{2}$ (b) $15 \mathrm{MeV} \mathrm{Si}$, fluence $350 \mathrm{tracks} / \mu \mathrm{m}^{2}$ (c) $6 \mathrm{MeV} \mathrm{Si}$, fluence $350 \mathrm{tracks} / \mu \mathrm{m}^{2}$ (d) $3 \mathrm{MeV} \mathrm{O}$, fluence $350 \mathrm{tracks} / \mu \mathrm{m}^{2}$. Corresponding GISAXS maps measured with the x-ray beam set (e)-(h) parallel to the ion tracks $\left(\theta=0^{\circ}\right)$ and (i)-(1) under the angle of $\theta=5^{\circ}$ with the tracks. (m) schematics of the Model 3 used in the analysis of nanoscale ripples. 


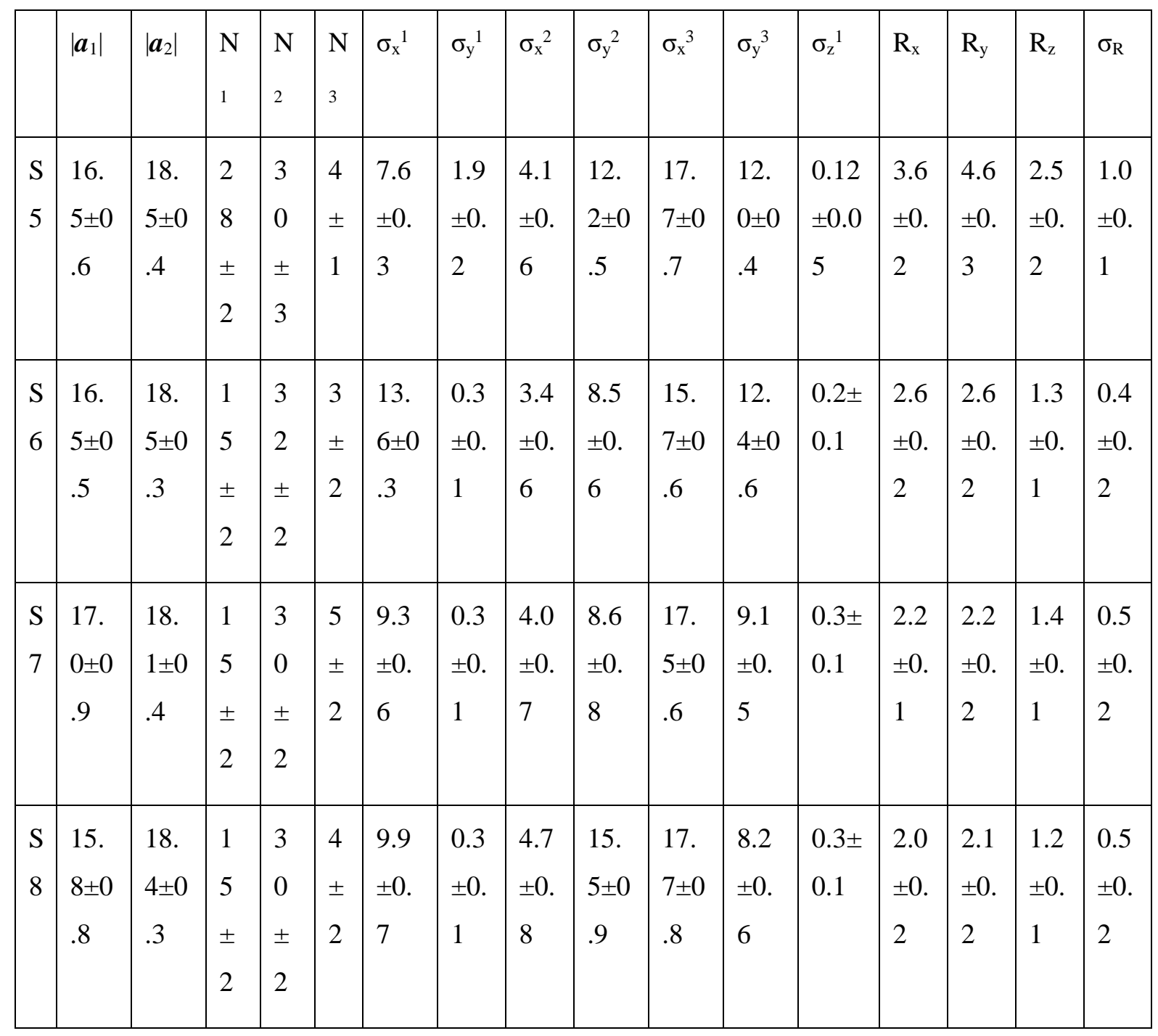

Table 3. Structural properties of the high-fluence ion tracks (samples S5-S8). The basis vectors $\boldsymbol{a}_{1}, \boldsymbol{a}_{2}$ define the ideal positions of the nanohillocks in the lattice. $\mathrm{N}_{1}, \mathrm{~N}_{2}$ are the number of nanohillock periods in $\mathrm{x}$ and $\mathrm{y}$ directions, respectively, while $\mathrm{N}_{3}$ is the number of super periods in y direction. The disorder parameters $\sigma_{\mathrm{x}-\mathrm{z}}{ }^{1}$ and $\sigma_{\mathrm{x}-\mathrm{z}}{ }^{2}$ and $\sigma_{\mathrm{x}-\mathrm{z}}{ }^{3}$ describe the deviation of the nanohillock positions from the ideal ones. $R_{\mathrm{x}}, R_{\mathrm{y}}$ and $R_{\mathrm{z}}$ are nanohillock radii in $x, y$, and $z$ directions respectively, $\sigma_{\mathrm{R}}$ is the standard deviation of the size distribution. All values except $\mathrm{N}_{1}-\mathrm{N}_{3}$ (dimensionless) are given in $\mathrm{nm}$. 


\section{Etching and annealing of the ion tracks}

The fabrication of surface tracks is not limited to ITO. With the right ion beam, it can be performed in almost any dielectric material and even many semiconductors. The procedure is thus viable for any application requiring nanopatterned insulators. For application purposes it is however crucial to know how stable the ion induced nanostructures are with respect to frequent post-processing steps such as etching or annealing. To study the etching behaviour we have chosen $\mathrm{SrTiO}_{3}$ single crystals which are an important oxide material for growing high quality epitaxial films for electronics. This prototypical perovskite is known to be chemically etchable by various etchants, where most often used are HF based etchants [51]. This way, a $\mathrm{TiO}_{2}$ terminated surface can be obtained without etch pits and with atomic flat terraces. Here we report results of ion track etching in $\mathrm{SrTiO}_{3}$.

Ion tracks on $\mathrm{SrTiO}_{3}(100)$ surfaces exhibit a decidedly discontinuous morphology, i.e. they consist of nanohillocks equally spaced along the SHI trajectory. We have shown previously $[23,56]$ that grazing incidence SHI irradiation using the 6 MV Tandem Van de Graaff accelerator at the RBI accelerator facility can successfully produce ion tracks even in bulk $\mathrm{SrTiO}_{3}$. In this work we have used the same $23 \mathrm{MeV}$ I beam to produce well developed, discontinuous ion tracks on the $\mathrm{SrTiO}_{3}$ surface, as shown by the AFM images in Fig. 4(a,b). These surface tracks are typically a few hundred nanometers in length and a few nanometers high. The typical nanohillock diameters of tens of nanometer, as well as the nanohillocks spacings, are also well in agreement with previously reported values [21-23,61]. The exposure of the $\mathrm{SrTiO}_{3}$ surface to a higher fluence irradiation results in overlapping ion tracks also shown in Fig. 4(b,c). The irradiated samples were etched in $\mathrm{HNO}_{3}$ based etchant [53] for 20 minutes, and imaged afterwards by AFM, see Fig. 4(d-f). These images clearly reveal nanoholes. Apparently, the nanohillocks consisted of amorphous or at least sufficiently disordered material which has been successfully removed by the etching procedure. The high etching selectivity, i.e. resistivity of the pristine $\mathrm{SrTiO}_{3}$ to the etchant, yields a well-defined shape of the etched surface ion tracks. Also, overlapping ion tracks obtained after high fluence irradiation can be completely etched away. However, in this case the surface morphology does not offer much in terms of uniformity or periodicity.

It is known that the finite radius of the AFM tip will overestimate the nanohillock diameter, but not the height [62]. In the present work where nanoholes have to be imaged, the effects of the AFM tip radius can be even more detrimental, since both the nanohole diameter and depth measurements can be affected. Therefore, a further characterization of the etched 
surface ion tracks has been done by TEM and HRTEM. Fig 4 (g) shows an HAADF STEM image of a grazing ion track on the surface of $\mathrm{SrTiO}_{3}$ in cross section. The ion direction was from left to right (as depicted by the white arrow) and the bottom edge of the brighter zone represents the irradiated surface. The dark contrast below the bright zone is due to amorphous carbon deposition during the FIB based lamella extraction in order to protect the surface from ion damage. The HAADF signal is sensitive to the average projected atomic number with regions of higher average $\mathrm{Z}$ appearing brighter. The projected specimen thickness in the imaged region was on the order of about $40 \mathrm{~nm}$ resulting in the etched features being embedded within the foil but displaying darker contrast due to the reduction in the number of atoms in the projected columns. Regions of slightly darker contrast (indicated by vertical arrows) can be seen to form triangular zones just below the irradiated surface increasing in size and depth from left to right along the ion path and appear reasonably evenly spaced. The triangular projection is consistent with the findings of [63] that (100) etched $\mathrm{SrTiO}_{3}$ surfaces produce pyramidal etch pits with basal edges along $\{100\}$. Fig $4(h)$ shows a higher magnification region of the same specimen. Again, the triangular etch pits are clearly visible but the fact that they have no atomically sharp edges also supports the conclusion of ref. [63] that no preferred facet is revealed during etching. Also noteworthy is the absence of a buried cylindrical amorphous track as is common in the bulk after normal irradiation at sufficiently high electronic stopping power. 

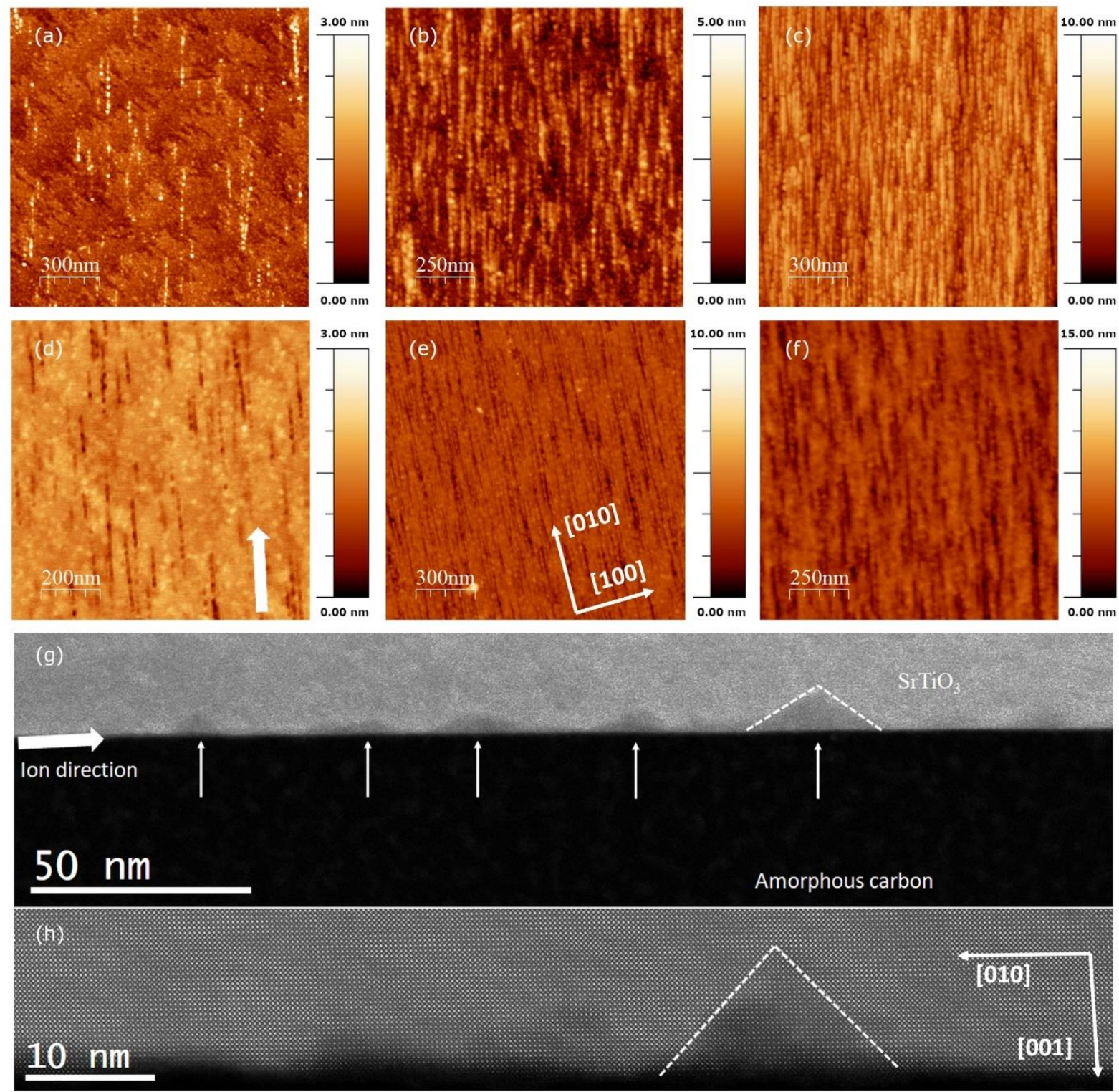

Figure 4. (a-c) AFM images from $\mathrm{SrTiO}_{3}$ surfaces irradiated with a $23 \mathrm{MeV}$ I beam irradiation at grazing incidence angle (arrow marks direction of the SHI beam, incidence angle $\phi=1^{\circ}$ ), with increasing fluences of a) 30, b) 120 , and c) 500 ion tracks $/ \mu m^{2}$. (d-f) Etched surface of irradiated $\mathrm{SrTiO}_{3}$ exposed to the same ion fluence as above. (g) HAADF STEM image of an etched ion track on $\mathrm{SrTiO}_{3}$ surface (h) atomic resolution HAADF STEM image of an etched ion track on $\mathrm{SrTiO}_{3}$ surface. The image plane of the STEM images is parallel to the (100) plane of the crystal. Relative crystallographic directions are shown on the HRSTEM image as well as 3(e) from which it was extracted. 
For our annealing study, we have chosen $\mathrm{SiO}_{2}$ as material because it is a material quite well investigated with respect to the annealing of ion tracks in the bulk [52,64-66]. Also, surface ion tracks may be produced in both $\mathrm{a}_{-} \mathrm{SiO}_{2}$ and quartz $\mathrm{SiO}_{2}$ with a $23 \mathrm{MeV}$ I beam [67]. Furthermore, $\mathrm{SiO}_{2}$ is often used as substrate for graphene, a material where grazing incidence irradiation with SHI may be used to perforate graphene [46]. For graphene deposited on $\mathrm{SiO}_{2}$, it has been shown that charge transfer from the substrate occurs [68] and that SHI induced folding can be prevented by annealing the system presumably by removing intercalated water [69]. As shown by the AFM images in Figs. 5 and 6, surface ions tracks are well developed after irradiation, and a moderately high fluence of $\sim 200 \mathrm{tracks} / \mu \mathrm{m}^{2}$ results in nanoscale ripplelike patterning of the surface. Two sets of samples, one $\mathrm{a}-\mathrm{SiO}_{2}$ and another quartz (crystalline) $\mathrm{SiO}_{2}$, have been exposed to the same $23 \mathrm{MeV}$ I beam at a grazing incidence angle of $\phi=1^{\circ}$, and the same fluence. Both sets of samples have later been annealed in vacuum $\left(10^{-5} \mathrm{mbar}\right)$ for one hour, at various temperatures.

In the case of quartz $\mathrm{SiO}_{2}$, the surface ion tracks exhibited high thermal stability. As shown in Fig. 5(b-d), the ion tracks started to fade only between $750^{\circ} \mathrm{C}-850^{\circ} \mathrm{C}$. It appears that at these temperatures their height has decreased, but the number density of tracks per area remains the same. Only for the highest temperature used in this study $\left(950^{\circ} \mathrm{C}\right)$, the tracks have been almost completely erased, but even then, some of their remains can still be observed, see Fig. 5(d). Ion tracks in amorphous $\mathrm{SiO}_{2}$ were found to be less thermally stable than in quartz. As demonstrated by the AFM images shown in Fig. 6(b-d), a similar process occurs - however, at much lower temperatures. Annealing at $500^{\circ} \mathrm{C}$ and $550^{\circ} \mathrm{C}$ leads to a decrease of the surface ion track height, and annealing at $650^{\circ} \mathrm{C}$ leads to complete erasure of the surface ion tracks. 

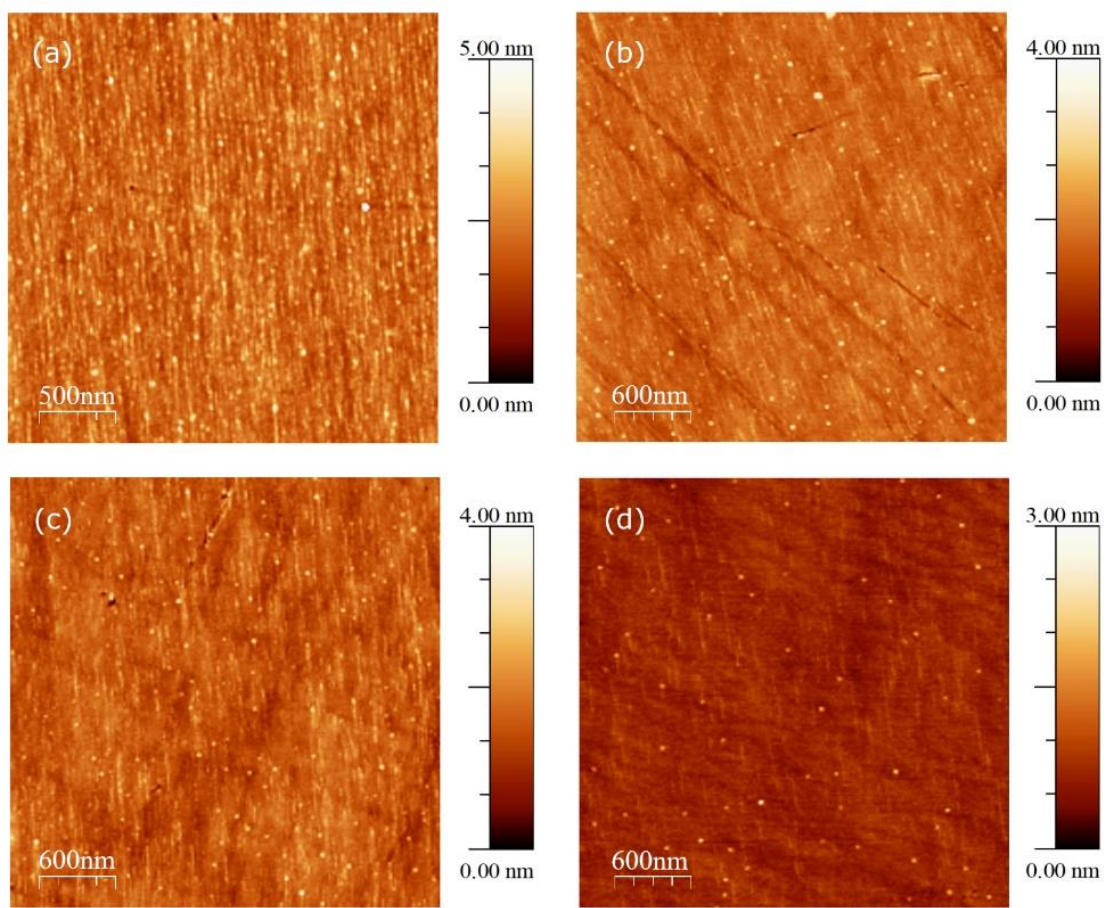

Figure 5. Ion tracks on quartz $\mathrm{SiO}_{2}$ surface produced by $23 \mathrm{MeV}$ I irradiation at grazing incidence angle $\left(\phi=1^{\circ}\right)$ : (a) before annealing, (b) after annealing at $750^{\circ} \mathrm{C}$, (c) after annealing at $850^{\circ} \mathrm{C},(\mathrm{d})$ after annealing at $950^{\circ} \mathrm{C}$.
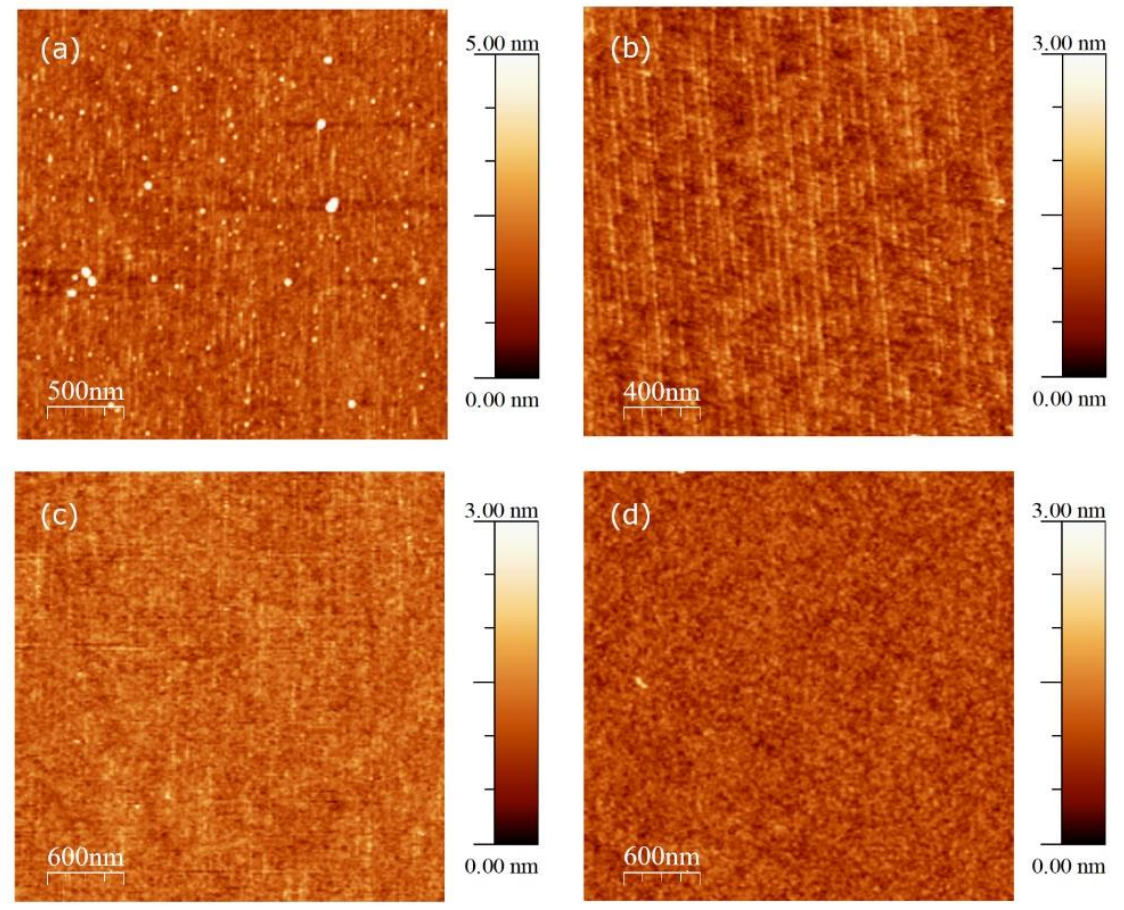

Figure 6. Ion tracks on a-SiO $\mathrm{S}_{2}$ surface produced by $23 \mathrm{MeV}$ I irradiation at grazing incidence angle $\left(\phi=1^{\circ}\right)$ : (a) before annealing, (b) after annealing at $500^{\circ} \mathrm{C}$, (c) after annealing at $550^{\circ} \mathrm{C}$, (d) after annealing at $650^{\circ} \mathrm{C}$. 


\section{DISCUSSION}

Previously, we have reported that high fluence SHI irradiation can be used to design quantum dot lattices in amorphous multilayers [70-74]. But in contrast to those works, where incidence angles between $30^{\circ}$ and $90^{\circ}$ with respect to the surface have been used [72], irradiation at grazing incidence angle of only $1^{\circ}$ produces periodic ripple-like pattern on the surface already at moderate fluences as shown here. For this completely new approach we could identify suitable irradiation parameters to obtain nanoscale ripples of high quality. In case when the electronic stopping is too low (for example at $2.4 \mathrm{keV} / \mathrm{nm}$ in case of irradiation with $3 \mathrm{MeV} \mathrm{O}$ beam), the surface morphology remains practically unaltered. On the other hand, if the electronic stopping is too high (for example at $8.1 \mathrm{keV} / \mathrm{nm}$ in case of $23 \mathrm{MeV}$ I beam), the surface becomes rugged and the quality of the ripples is poor. Still, more work needs to be done to clarify ion track overlap kinetics, i.e. how high fluence of overlapping ion tracks is needed to produce ripples. We note the mechanisms of ripple formation is altogether different than mechanisms at work during low energy keV ion sputtering, hence typical methods developed there (like for example rotating the sample around the surface normal during irradiations) will probably not work.

Another finding reported here is the appearance of nanostripes (i.e. „,doubletracks“) at low irradiation fluences, and above certain electronic stopping of the SHI. In the present study we observe them at $21 \mathrm{keV} / \mathrm{nm}$, but not at $8.1 \mathrm{keV} / \mathrm{nm}$, i.e. nanostripes have been observed after $92 \mathrm{MeV}$ Xe ion irradiation, but not after $23 \mathrm{MeV}$ I irradiation. Double tracks have been reported before but these were found either as the typical track morphology in a certain material [33] or in front of a surface track [32]. Here we have shown that it is indeed possible to switch between the two morphologies by choosing the proper irradiation parameters. For now it remains unclear whether this is characteristic for the chosen material or if this could be achieved also for the other materials if the beam energy was varied over a sufficiently large range. In any case, for $\mathrm{SrTiO}_{3}$ e.g., this switching has not been observed [23]. Further progress in surface nanostructuring can probably be achieved in a similar manner in the case of $2 \mathrm{D}$ materials, when the thickness of the material itself can yield different ion track morphologies [38].

Etching of surface ion tracks in $\mathrm{SrTiO}_{3}$ demonstrated an excellent etching selectivity, revealing ion tracks in $\mathrm{SrTiO}_{3}$ to be amorphous, or at least containing highly disordered material. While etching is a well-known technique for post-processing of ion tracks, to the best of our knowledge, only surface ion tracks in $\mathrm{a}-\mathrm{SiO}_{2}$ [26] and $\mathrm{SiC}$ [30] have been etched 
previously. In the latter case, etching of $\mathrm{SiC}$ after the irradiation was done to remove the oxide layer, and to establish the presence of a grove as surface ion track morphology in SiC. Therefore, the etching itself has not been used to "develop" the ion tracks after SHI irradiation. In the first case, ion tracks in $\mathrm{a}-\mathrm{SiO}_{2}$ have exhibited less pronounced variations along them (due to the amorphous structure of the material), and consequently etched ion tracks are long groves with an almost cylindrical in shape. Etched surface ion tracks in $\mathrm{SrTiO}_{3}$, on the other hand, have a well-defined, characteristic morphology, and the presented method offers a facile way to produce equidistant nanosized holes on the surface of the dielectric material. This method most likely can be used for other crystalline insulators as well, where surface ion tracks appear in similar shapes [24], however suitable etchants with high selectivity have to be found first.

The etching of surface ion tracks offers another advantage over the etching of the tracks in the bulk, performed after normal incidence SHI irradiation. For successful etching of the ion tracks in the bulk, the morphology of the track needs to be continuous. Only then may the etchant freely move inwards into the bulk and dissolve damaged material. However, to produce a continuous ion track, the electronic stopping has to be sufficiently higher than the threshold value [75]. Therefore, etching of surface tracks is easier to achieve because discontinuous tracks can also be etched away, which again means that lower stopping powers suffice, i.e. smaller accelerators can be used. Furthermore, producing nanoholes is possible only in the case of surface tracks, because ion tracks in the bulk with a discontinuous morphology are not etchable. In the case of high fluences, etching did not yield well-ordered nanoscale ripples in $\mathrm{SrTiO}_{3}$. Further work should be done in this regard, probably by choosing another material like a-SiO 2 where ion tracks would be continuous. Finally, observing directly a single etched ion track on the surface by means of HRTEM, offers another piece of information about the surface ion track formation process $[61,76]$. Most importantly, it seems the material that contributes to forming the nanohillock on the material surface, does not originate from large depth, at least in the case of grazing SHI irradiations [77].

Annealing is another post-irradiation process used in conjunction with ion irradiation, e.g., to anneal unwanted irradiation damage obtained during sputter cleaning or in thermochronology. However, annealing studies have also taken place in more fundamental research, especially in the case of a-SiO 2 [52] and quartz $\mathrm{SiO}_{2}$ [64-66]. The disappearance of the ion tracks both in a- $\mathrm{SiO}_{2}$ at $650^{\circ} \mathrm{C}$ and their fading in quartz $\mathrm{SiO}_{2}$ at $950^{\circ} \mathrm{C}$ agree with previous works on annealing of ion tracks in the bulk. Therefore, we tentatively conclude that the surface plays only a minor role, if any, during the ion tracks annealing. A more dedicated 
study would be of interest to establish this with certainty because recently, recrystallisation has been identified as an important process during the ion track formation [42], and the surface might play a more prominent role also in the track annealing. From the point of applications, the possible disappearance of tracks with increasing temperature might be a disadvantage if a thermally stable nanopattern is required and has to be accounted for, e.g., by the proper choice of a substrate material. Alternative solution could be use of nanopatterned surface as a template for the production of replica that is more thermally stable.

\section{CONCLUSIONS}

A novel route for the production of nanoscale ripple patterns on a large surface area by using SHI irradiation at grazing incidence angles has been demonstrated. This method is cost and time effective, as exposure times are typically in a range of only a few minutes. While high energy accelerators delivering SHIs have already found industrial applications like the production of track etched polycarbonate membranes, even small-scale accelerators like the 1 MV Tandetron accelerator available at the RBI can be used for the surface nanopatterning. Our research proves that the approach presented here is also applicable for other materials like $\mathrm{TiO}_{2}$ [27], thus avoiding a limitation in the use of binary compounds [9]. Further treatment of the irradiated surfaces (annealing, etching, ion beam sputtering) can lead to an even better nanoripple morphology in terms of homogeneity and periodicity.

New opportunities for applications where surface nanostructuring is needed, like manipulating surface adhesion and wettability can be offered. Also, nanoscale rippled substrates can be used as templates for ordered growth of nanoparticles [19,20], for stimulating cell growth on biocompatible surfaces [78] or for influencing the properties of 2D materials such as graphene [79] and $\mathrm{MoS}_{2}$ [80] via substrate morphology manipulation. Therefore, from the application perspective, nanoscale patterning by grazing incidence SHI offers unique opportunities with excellent control over many parameters, both for surface $[21,30]$ and $2 \mathrm{D}$ materials nanostructuring [35,69].

\section{ACKNOWLEDGEMENTS}

This work was supported by the Croatian Science Foundation (HRZZ pr. no. 2786). The authors acknowledge financial support from the European Regional Development Fund for the 'Center of Excellence for Advanced Materials and Sensing Devices' (Grant No. 
KK.01.1.1.01.0001)". The authors acknowledge the CERIC-ERIC Consortium for the access to the experimental facilities and financial support. This work is partially supported by the IAEA research contract No. 23009. This work has been realized also by an experiment performed at Grand Accélérateur National d'Ions Lourds (GANIL) Caen, France, and supported by the French Network EMIR\&A. This work has been supported by the Interdisciplinary Center for Analytics on the Nanoscale (ICAN), a core facility funded by the DFG (reference RI_ 00313). This research has received funding from the European Community's Seventh Framework Programme (FP7/2007-2013) - CALIPSO - pr. No. 312284. Partial financing from the Slovenian research agency via P2-0084 program is gratefully acknowledged.

\section{REFERENCES}

[1] S. Facsko, T. Dekorsy, C. Koerdt, C. Trappe, H. Kurz, A. Vogt and H.L. Hartnagel, Formation of Ordered Nanoscale Semiconductor Dots by Ion Sputtering, Science 285 (1999) 1551.

[2] U. Valbusa, C. Boragno and F. Buatier de Mongeot, Nanostructuring surfaces by ion sputtering, J. Phys.: Condens. Matter 14 (2002) 8153.

[3] W.L. Chan and E. Chason, Making waves: Kinetic processes controlling surface evolution during low energy ion sputtering, J. Appl. Phys. 101 (2007) 121301.

[4] J. Munoz-Garcia, L. Vázquez, M. Castro, R. Gago, A. Redondo-Cubero, A. Moreno Barrado and R. Cuerno, Self-organized nanopattrening of silicon surfaces by ion beam sputtering, Mat. Sci. Eng. R 86 (2014) 1.

[5] G. Carter, The physics and applications of ion beam erosion, J. Phys. D: Appl. Phys. 34 (2001) R1.

[6] V.B. Shenoy, W.L. Chan, E. Chason, Compositionally Modulated Ripples Induced by Sputtering of Alloy Surfaces, Phys. Rev. Lett. 98 (2007) 256101.

[7] F. Frost, B. Ziberi, A. Schindler and B. Rauschenbach, Appl. Phys. A 91 (2008) 551.

[8] B. Ziberi, M. Cornejo, F. Frost and B. Rauschenbach, Highly ordered nanopatterns on Ge and Si surfaces by ion beam sputtering, J. Phys.: Condens. Matter 21 (2009) 224003. 
[9] R.M. Bradley and P.D. Shipman, Spontaneous Pattern Formation Induced by Ion Bombardment of Binary Compounds, Phys. Rev. Lett. 105 (2010) 145501.

[10] S.A. Mollick, D. Ghose, P.D. Shipman and R.M. Bradley, Anomalous patterns and nearly defect-free ripples produced by bombarding silicon and germanium with a beam of gold ions, Appl. Phys. Lett. 104 (2014) 043103.

[11] S. Lee, L. Wang and W. Lu, Self-organized chains of nanodots induced by an off-normal incident beam, Nanoscale Res. Lett. 6 (2011) 432.

[12] S. Lee, L. Wang and W. Lu, Formation of ordered nanodroplet chains on a solid surface by enhanced surface diffusion and shadow effect, Surf. Sci. 606 (2012) 659.

[13] A. Redinger, S. Standop, T. Michely, Y. Rosandi and H.M. Urbassek, Trails of Kilovolt Ions Created by Subsurface Channeling, Phys. Rev. Lett. 104 (2010) 075501.

[14] A. Redinger, S. Standop, Y. Rosandi, H.M. Urbassek and T. Michely, Making channeling visible: keV noble gas ion trails on Pt(111), New. J. Phys. 13 (2011) 013002.

[15] S. Standop, O. Lehtinen, C. Herbig, G. Lewes-Malandrakis, F. Craes, J. Kotakoski, T. Michely, A.V. Krasheninnikov and C. Busse, Ion Impacts on Graphene/Ir(111): Interface Channeling, Vacancy Funnels, and a Nanomesh, Nano Lett. 13 (2013) 1948.

[16] R. Böttger, K.-H. Heinig, L. Bischoff, B. Lietke, R. Hübner and W. Pilz, Silicon nanodot formation and self-ordering under bombardment with heavy $\mathrm{Bi}_{3}$ ions, Phys. Status Solidi Rapid Res. Lett. 7 (2013) 501.

[17] L. Bischoff, R. Böttger, K.-H. Heinig, S. Facsko, W. Pilz, Surface patterning of GaAs under irradiation with very heavy polyatomic Au ions, Appl. Surf. Sci. 310 (2014) 154.

[18] A. Biermanns, U. Pietsch, J. Grenzer, A. Hanisch, S. Facsko, G. Carbone and T. H. Metzger, X-ray scattering and diffraction from ion beam induced ripples, J. Appl. Phys. 104 (2008) 044312.

[19] M. Buljan, J. Grenzer, V. Holý, N. Radić, T. Mišić-Radić, S. Levichev, S. Bernstorff, B. Pivac, I. Capan, Structural and charge trapping properties of two bilayer $\left(\mathrm{Ge}+\mathrm{SiO}_{2}\right) / \mathrm{SiO}_{2}$ films deposited on rippled substrate, Appl. Phys. Lett. 97 (2010) 163117.

[20] M. Buljan, J. Grenzer, A. Keller, N. Radić, V. Valeš, S. Bernstorff, T. Cornelius, H. T. Metzger and V. Holý, Growth of spatially ordered Ge nanoclusters in an amorphous matrix on rippled substrates, Phys. Rev. B 82 (2010) 125316. 
[21] E. Akcöltekin, T. Peters, R. Meyer, A. Duvenbeck, M. Klusmann, I. Monnet, H. Lebius and M. Schleberger, Creation of multiple nanodots by single ion, Nature Nanotech. 2 (2007) 290.

[22] E. Akcöltekin, S. Akcöltekin, O. Osmani, A. Duvenbeck, H. Lebius and M. Schleberger, Swift heavy ion irradiation of $\mathrm{SrTiO}_{3}$ under grazing incidence, New J. Phys. 10 (2008) 053007.

[23] M. Karlušić, S. Akcöltekin, O. Osmani, I. Monnet, H. Lebius, M. Jakšić and M. Schleberger, Energy threshold for the creation of nanodots on $\mathrm{SrTiO}_{3}$ by swift heavy ions, New J. Phys. 12 (2010) 043009.

[24] S. Akcöltekin, E. Akcöltekin, T. Roll, H. Lebius and M. Schleberger, Patterning of insulating surfaces by electronic excitation, Nucl. Instrum. Meth. Phys. Res. B 267 (2009) 1386.

[25] A.M.J.F. Carvalho, M. Marinoni, A.D. Touboul, C. Guasch, H. Lebius, M. Ramonda, J. Bonnet and F. Saigne, Discontinuous ion tracks on silicon oxide on silicon surfaces after grazing angle heavy ion irradiation, Appl. Phys. Lett. 90 (2007) 073116.

[26] A.M.J.F. Carvalho, A.D. Touboul, M. Marinoni, J.-F. Carlotti, C. Guasch, M. Ramonda, H. Lebius, F. Saigne and J. Bonnet, $\mathrm{SiO}_{2}-\mathrm{Si}$ under swift heavy ion irradiation. A comparison between normal and grazing incidence features, Nucl. Instrum. Meth. Phys. Res. B 266 (2008) 2981.

[27] M. Karlušić, S. Bernstorff, Z. Siketić, B. Šantić, I. Bogdanović-Radović, M. Jakšić, M. Schleberger, M. Buljan, Formation of swift heavy ion tracks on rutile $\mathrm{TiO}_{2}(001)$ surface, J. Appl. Cryst. 49 (2016) 1704.

[28] R.M. Papaleo, M.R. Silva, R. Leal, P.L. Grande, M. Roth, B. Schattat and G. Schiwietz, Direct evidence for Projectile Charge-State Dependent Crater Formation Due to Fast Ions, Phys. Rev. Lett. 101 (2008) 167601.

[29] R.M. Papaleo, R. Thomaz, L.I. Gutierres, V.M. de Menzes, D. Severin, C. Trautmann, D. Tramontina, E.M. Bringa and P.L. Grande, Confinement Effects of Ion Tracks in Ultrathin Polymer Films, Phys. Rev. Lett. 114 (2015) 118302.

[30] O. Ochedowski, O. Osmani, M. Schade, B. Kleine Bussmann, B. Ban-d'Etat, H. Lebius and M. Schleberger, Graphitic nanostripes in silicon carbide surfaces created by swift heavy ion irradiation, Nature Comm. 5 (2014) 3913. 
[31] M. Karlušić, R. Kozubek, H. Lebius, B. Ban-d'Etat, R.A.Wilhelm, M. Buljan, Z. Siketić, F. Scholz, T. Meisch, M. Jakšić, S. Bernstorff, M. Schleberger, B. Šantić, Response of GaN to energetic ion irradiation - conditions for ion track formation J. Phys. D: Appl. Phys. 48 (2015) 325304.

[32] F. Meinerzhagen, L. Breuer, H. Bukowska, M. Bender, D. Severin, M. Herder, H. Lebius, M. Schleberger, A. Wucher, A new setup for investigation of swift heavy ion induced particle emission and surface modifications, Rev. Sci. Instr, 87 (2016) 013903.

[33] E. Gruber, L. Bergen, P. Salou, E. Lattouf, C. Grygiel, Y. Wang, A. Benyagoub, D. Lavavasseur, J. Rangama, H. Lebius, B. Ban-d'Etat, M. Schleberger, F. Aumayr, High resolution AFM studies of irradiated mica-following the traces of swift heavy ions under grazing incidence, J. Phys.: Cond. Matter 30 (2018) 285001.

[34] L. Madauß, I. Zegkinoglou, H.V. Muiños, Y.-W. Choi, S. Kunze, M.-Q. Zhao, C.H. Naylor, P. Ernst, E. Pollmann, O. Ochedowski, H. Lebius, A. Benyagoub, B. Ban-d'Etat, A.T.C. Johnson, F. Djurabekova, B. Roldan Cuenya, M. Schleberger, Highly active singlelayer $\mathrm{MoS}_{2}$ catalysts synthesized by swift heavy ion irradiation, Nanoscale, 10 (2018) 22908.

[35] S. Akcöltekin, H. Bukowska, T. Peters, O. Osmani, I. Monnet, I. Alzaher, B. Ban-d'Etat, H. Lebius and M. Schleberger, Unzipping and folding of graphene by swift heavy ions, Appl. Phys. Lett. 98 (2011) 103103.

[36] O. Ochedowski, H. Bukowska, V.M. Freire Soler, L. Brökers, B. Ban-d'Etat, H. Lebius and M. Schleberger, Folding two dimensional crystals by swift heavy ion irradiation, Nucl. Instrum. Meth. Phys. Res. B 340 (2014) 39.

[37] L. Madauß, O. Ochedowski, H. Lebius, B. Ban-d'Etat, C.H. Naylor, A.T.C. Johnson, J. Kotakoski, M. Schleberger, Defect engineering of single- and few-layer $\mathrm{MoS}_{2}$ by swift heavy ion irradiation, 2D Materials 4 (2017) 015034.

[38] M. Schleberger, J. Kotakoski, 2D material science: Defect engineering by Particle Irradiation, Materials 11 (2018) 1885.

[39] M. Toulemonde, W. Assmann, C. Dufour, A. Meftah, C. Trautmann, Nanometric transformation of the matter by short and intense electronic excitation - Experimental data versus inelastic thermal spike model, Nucl. Instr. Meth. Phys. Res. B 277 (2012) 28 
[40] N. Itoh, D. M. Duffy, S. Khakshouri and A.M. Stoneham, Making tracks: electronic excitation roles in forming swift heavy ion tracks, J. Phys.: Condens. Matter 21 (2009) 474205.

[41] F. Aumayr, S. Facsko, A.S. El-Said, C. Trautmann and M. Schleberger, Single ion induced surface nanostructures: a comparison between slow highly charged and swift heavy ions, J. Phys.: Condens. Matter 23 (2011) 393001.

[42] R.A. Rymzhanov, N. Medvedev, J.H. O’Connell, A.J. van Vuuren, V.A. Skuratov, A.E. Volkov, Recrystallization as the governing mechanism of ion track formation, Sci. Rep. 9 (2019) 3837.

[43] D. Fink (Ed.), Transport Processes in Ion-Irradiated Polymers (Springer, 2004).

[44] L. Madauß, J. Schumacher, M. Ghosh, O. Ochedowski, J. Meyer, H. Lebius, B. Band'Etat, M.E. Tomil-Molares, C. Trautmann, R.G.H. Lammertink, M. Ulbricht, M.

Schleberger, Fabrication of nanoporous graphene/polymer composite membranes, Nanoscale 9 (2017) 10487.

[45] U. Amaldi, G. Kraft, Radiotherapy with beams of carbon ions, Rep. Prog. Phys. 68 (2005) 1861.

[46] O. Ochedowski, O. Lehtinen, U. Kaiser, A. Turchanin, B. Ban-d’Etat, H. Lebius, M. Karlušić, M. Jakšić, and M. Schleberger, Nanostructuring Graphene by Dense Electronic Excitation, Nanotechnology 26 (2015) 465302.

[47] A.M.J.F. Carvalho, A.D. Touboul, M. Marinoni, M. Ramonda, C. Guasch, F. Saigne, J. Bonnet and J. Gasiot, Oxide thickness dependence of swift heavy ion-induced surface tracks formation in silicon dioxide on silicon structures at grazing incidence, J. Appl. Phys. 102 (2007) 124306.

[48] W.J. Weber, R.C. Ewing, C.R.A. Catlow, T. Diaz de la Rubia, L.W. Hobbs, C. Kinoshita, Hj. Matzke, A.T. Motta, M. Nastasi, E.K.H. Salje, E.R. Vance, S.J. Zinkle, Radiation effects in crystalline ceramics for the immobilization of high-level nuclear waste and plutonium, J. Mater. Res. 13 (1998) 1434.

[49] M. Karlušić, M. Škrabić, M. Majer, M. Buljan, V.A. Skuratov, H.K. Jung, O. Gamulin, M. Jakšić, Infrared spectroscopy of ion tracks in amorphous $\mathrm{SiO} 2$ and comparison to gamma irradiation induced changes, J. Nucl. Mater. 514 (2019) 74. 
[50] A.H. Mir, S. Peuget, Using external irradiations for simulating self-irradiation damage in nuclear waste glasses: State of the art, recommendations and prospects, J. Nucl. Mater. 539 (2020) 152246.

[51] M. Kawasaki, K. Takahashi, T. Maeda, R. Tsuchiya, M. Shinohara, O. Ishiyama, T. Yonezawa, M. Yoshimoto, H. Koinuma, Atomic Control of the $\mathrm{SrTiO}_{3}$ Crystal Surface, Science 266 (1994) 1540.

[52] K. Awazu, S. Ishii, K. Shima, S. Roorda, J.L. Brebner, Structure of latent tracks created by swift heavy-ion bombardment of amorphous $\mathrm{SiO}_{2}$, Phys. Rev. B 62 (2000) 3689.

[53] N. Matsuura, T.W. Simpson, I.V. Mitchell, X.-Y. Mei, P. Morales, H.E. Ruda, Ultrahigh-density, nonlithographic, sub-100 $\mathrm{nm}$ pattern transfer by ion implantation and selective chemical etching, Appl. Phys. Lett. 81 (2002) 4826.

[54] J.F. Ziegler, M.D. Ziegler, J.P. Biersack, SRIM - the stopping and range of the ions in matter (2010), Nucl. Instr. Meth. Phys. Res. Sect. B 268 (2010) 1818.

[55] S.K. Choi, J.I. Lee, Effect of film density on electrical properties of indium tin oxide films deposited by dc magnetron reactive sputtering, J. Vac. Sci. Tech. A 19 (2001) 2043. [56] M. Karlušić, M. Jakšić, H. Lebius, B. Ban-d’Etat, R.A. Wilhelm, R. Heller, M. Schleberger, Swift heavy ion track formation in $\mathrm{SrTiO}_{3}$ and $\mathrm{TiO}_{2}$ under random, channeling and near-channeling conditions, J. Phys. D: Appl. Phys. 50 (2017) 205302.

[57] A. Meftah, F. Brisard, J.M. Constantini, E. Dooryhee, M. Hage-Ali, M. Hervieu, J.P. Stoquert, F. Studer, M. Toulemonde, Track formation in $\mathrm{SiO}_{2}$ quartz and the thermal-spike mechanism, Phys. Rev. B 49 (1994) 12457.

[58] M.L. Brongersma, E. Snoeks, A. Polman, Temperature dependence of MeV heavy ion irradiation-induced viscous flow in SiO2, Appl. Phys. Lett. 71 (1997) 1628.

[59] I. Horcas, R. Fernandez, J.M. Gomez-Rodriguez, J. Colchero, J. Gomez-Herrero, A.M. Baro, WSXM: A software for scanning probe microscopy and a tool for nanotechnology, Rev. Sci. Instr. 78 (2007) 013705.

[60] M. Buljan, M. Karlušić, N. Nekić, M. Jerčinović, I. Bogdanović-Radović, S.Bernstorff, N. Radić, I. Mekterović, GISAXS analysis of ion-beam modified films and surfaces, Comp. Phys. Comm. 212 (2017) 69. 
[61] A. Kitamura, N. Ishikawa, K. Kondo, S. Yamamoto, T. Yamaki, FE-SEM observation of chains of nanohillocks in $\mathrm{SrTiO}_{3}$ and $\mathrm{Nb}$-doped $\mathrm{SrTiO}_{3}$ surfaces irradiated with swift heavy ions, Nucl. Instr. Meth. Phys. Res. B 460 (2019) 175.

[62] N. Khalfaoui, C.C. Rotaru, S. Bouffard, M. Toulemonde, J.P. Stoquert, F. Haas, C. Trautmann, J. Jensen, A. Dunlop, Characterization of swift heavy ion tracks in $\mathrm{CaF}_{2}$ by scanning force and transmission electron microscopy, Nucl. Instr. Meth. Phys. Res. B 240 (2005) 819.

[63] G.C. Spalding, W.L. Murphy, T.M. Davidsmeier, J.E. Elenovski, Faceting of Single Crystal $\mathrm{SrTiO}_{3}$ during Wet Chemical Etching, Mat. Res. Soc. Symp. 587 (2000) O6.4.1

[64] B. Afra, K. Nordlund, M.D. Rodriguez, T. Bierschenk, C. Trautmann, S. Mudie, P. Kluth, Thermal response of nanoscale cylindrical inclusions of amorphous silica embedded in a-quartz, Phys. Rev. B 90 (2014) 224108.

[65] D. Schauries, B. Afra, M.D. Rodriguez, C. Trautmann, A. Hawley, P. Kluth, Ion track annealing in quartz investigated by small angle X-ray scattering, Nucl. Instr. Meth. Phys. Res. B 365 (2015) 380.

[66] D. Schauries, A.A. Leino, B. Afra, M.D. Rodriguez, F. Djurabekova, K. Nordlund, N. Kirby, C. Trautmann, P. Kluth, Orientation dependent annealing kinetics of ion tracks in c$\mathrm{SiO}_{2}$, J. Appl. Phys. 118 (2015) 224305.

[67] M. Karlušić, S. Fazinić, Z. Siketić, T. Tadić, D.D. Cosic, I. Božičević-Mihalić, I. Zamboni, M. Jakšić, M. Schleberger, Monitoring ion track formation using in situ RBS/c, ToF-ERDA and HR-PIXE, Materials 10 (2017) 1041.

[68] Z.H. Ni, H.M. Wang, Z.Q. Luo, Y.Y. Wang, T. Yu, Y.H. Wu, Z.X. Shen, The effect of vacuum annealing in graphene, J. Raman Spectrosc. 41 (2010) 479.

[69] O. Ochedowski, B. Kleine Bussman, B. Ban-d'Etat, H. Lebius and M. Schleberger, Manipulation of the graphene surface potential by ion irradiation, Appl. Phys. Lett. 102 (2013) 153103.

[70] M. Buljan, I. Bogdanović-Radović, M. Karlušić, U.V. Desnica, G. Dražić, N. Radić, P. Dubček, K. Salamon, S. Bernstorff and V. Holý, Formation of long-range ordered quantum dots arrays in amorphous matrix by ion beam irradiation, Appl. Phys. Lett. 95 (2009) 063104. [71] M. Buljan, I. Bogdanović-Radović, M. Karlušić, U. V. Desnica, N. Radić, N. Skukan, G. Dražić, M. Ivanda,O. Gamulin, Z. Matej, V. Valeš, J. Grenzer, T. W. Cornelius, H. T. 
Metzger and V. Holý, Generation of an ordered Ge quantum dot array in an amorphous silica matrix by ion beam irradiation: Modeling and structural characterization, Phys. Rev. B 81 (2010) 085321.

[72] M. Buljan, I. Bogdanović-Radović, M. Karlušić, U. V. Desnica, N. Radić, M. Jakšić, K. Salamon, G. Dražić, S. Bernstorff and V. Holý, Design of quantum dot lattices in amorphous matrices by ion beam irradiation, Phys. Rev. B 84 (2011) 155312.

[73] M. Buljan, M. Karlušić, I. Bogdanović-Radović, M. Jakšić, N. Radić, K. Salamon, S. Bernstorff, Determination of ion track radii in amorphous matrices via formation of nanoclusters by ion-beam irradiation, Appl. Phys. Lett. 101 (2012) 103112.

[74] I. Bogdanović-Radović, M. Buljan, M. Karlušić, N. Skukan, I. Božičević, M. Jakšić, N. Radić, G. Dražić, S. Bernstorff, Conditions for formation of germanium quantum dots in amorphous matrices by $\mathrm{MeV}$ ions: Comparison with standard thermal annealing, Phys. Rev. B 86 (2012) 165316.

[75] J. Jensen, A. Razpet, M. Skupiński, G. Possnert, Ion tracks in amorphous $\mathrm{SiO}_{2}$ irradiated with low and high energy heavy ions, Nucl. Instr. Meth. Phys. Res. B 245 (2006) 269.

[76] N. Ishikawa, N. Okubo, T. Taguchi, Experimental evidence of crystalline hillocks by irradiation of $\mathrm{CeO}_{2}$ with swift heavy ions: TEM study, Nanotechnology 26 (2015) 355701.

[77] N. Ishikawa, T. Taguchi, A. Kitamura, G. Szenes, M.E. Tomil-Molares, C. Trautmann, TEM analysis of ion tracks and hillocks produced by swift heavy ions of different velocities in $\mathrm{Y}_{3} \mathrm{Fe}_{5} \mathrm{O}_{12}$, J. Appl. Phys. 127 (2020) 055902.

[78] R. Carbone, I. Marangi, A. Zanardi, L. Giorgetti, E. Chierici, G. Berlanda, A. Podestà, F. Fiorentini, G. Bongiorno, P. Piseri, P.G. Pelicci, P. Milani, Biocompatibility of clusterassembled nanostructured TiO2 with primary and cancer cells, Biomaterials 27 (2006) 3221. [79] S. Deng, V. Berry, Wrinkled, rippled and crumpled graphene: an overview of formation mechanism, electronic properties, and applications, Mat. Today 19 (2016) 197.

[80] V.S. Mangu, M. Zamiri, S.R.J. Brueck, F. Cavallo, Strain engineering, efficient excitonic photoluminescence, and exciton funneling in unmodified $\mathrm{MoS}_{2}$ sheets, Nanoscale 9 (2017) 16602. 